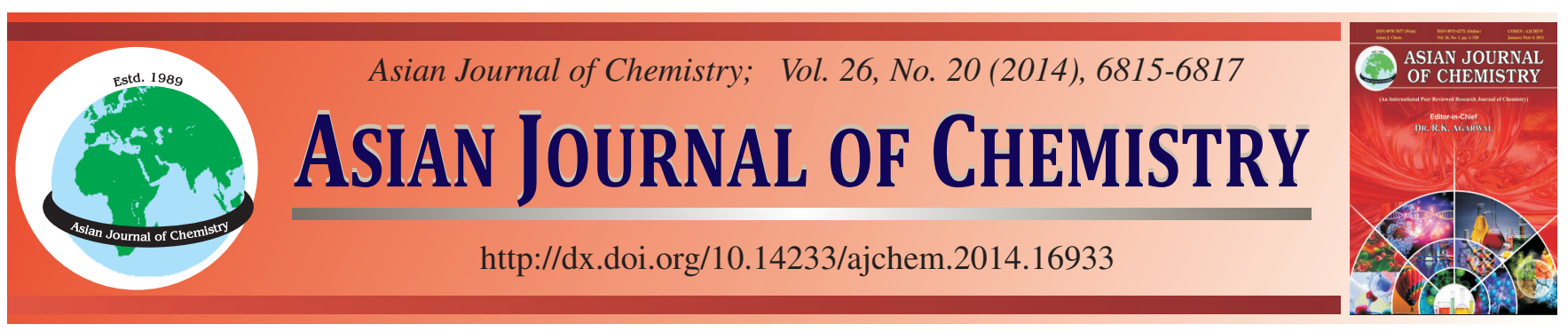

\title{
Synthesis of Glutathione Modified CdSe Quantum Dots and Its Application in Determination of Trace $\mathbf{H g}^{2+}$ Ions
}

Huacheng Wu, Jiangying Wang*, Jingu Zhang, Lejian Wang, Xuanrui Jia, Mingming He and Chongyuan Wang

College of Materials Science and Engineering, China Jiliang University, Hangzhou 310018, P.R. China

*Corresponding author: E-mail: wjyliu@163.com; zjjtongji@gmail.com

Received: 26 December 2013; $\quad$ Accepted: 25 February 2014; $\quad$ Published online: 25 September 2014; $\quad$ AJC-16016

\begin{abstract}
The water-soluble glutathione (GSH) modified CdSe quantum dots (QDs) were prepared. Results show that the optimum $\mathrm{NaBH}_{4}: \mathrm{Se}\left(\mathrm{Cd}^{2+}\right)$ : glutathione molar ratio is obtained to be 3:1:3:9. Meanwhile, the glutathione modified CdSe quantum dots synthesized by the optimum process have a single face centered cubic phase. It is found that the fluorescence quenching occurred as $\mathrm{Hg}^{2+}$ ions interact with glutathione modified CdSe quantum dots. $\mathrm{Hg}^{2+}$ ions can be determined in the concentration range of $0.3-15 \mu \mathrm{g} / \mathrm{L}$, which is proposed to determine the trace quantities of $\mathrm{Hg}^{2+}$ ions as fluorescence probe.
\end{abstract}

Keywords: CdSe, Quantum dots, Glutathione, Fluorescence probe.

\section{INTRODUCTION}

Nowadays, because of some human activities such as combustion and fusion of solid wastes, mercury directly enters to soil or water. Mercury in water contamination can enter the body of marines and then nutritious chain of human beings. Mercury(II) ion, as a hypertoxic heavy metal ion, poses a direct threat to the central nerve and endocrine systems ${ }^{1}$. Because of high poisonousness of $\mathrm{Hg}^{2+}$ ion, identification of ultra trace amounts of $\mathrm{Hg}^{2+}$ ions in environmental water and in the body of aquatics like fishes is of great importance and worthy of high attention to chemists. At present, there are many methods for detecting $\mathrm{Hg}^{2+}$ ions in water, such as cold-vapor atomic absorption spectrometry ${ }^{2}$, atomic fluorescence spectrometry ${ }^{3}$, inductively coupled plasma-mass spectrometry ${ }^{4}$, spectrophotometry ${ }^{5}$ and voltammetry ${ }^{6}$, etc. However, these methods are time-consuming for sample's preparation, expensive and require sophisticated equipment ${ }^{7}$. Therefore, simple, rapid and selective methods for detecting $\mathrm{Hg}^{2+}$ ions are still in demand.

Recently, semiconductor nanocrystals, often referred to as quantum dots, have attracted increasing attention due to their quantum confinement effect and remarkable optical, electrical properties ${ }^{8,9}$, which has been widely used in biology, medicine, analytical chemistry, especially in sensors ${ }^{10-12}$. The fluorescent properties of quantum dots are sensitive to their surface states, which can be used to detect heavy metal ions in aqueous solutions. When quantum dots are synthesized in aqueous solution, sulfhydryl compounds are often used as a modifier and stabilizer ${ }^{13,14}$. However, the sulfhydryl compounds are toxic substance and very sensitive to light, which is easy to fall off from the surface of quantum dots and then causes the agglomeration of quantum dots.

Glutathione (GSH) is a small molecule peptide found in most organisms and can be used to detoxify heavy metal ions in medicine due to its chelating capability ${ }^{15}$. Recently, glutathione has been also used in the synthesis of CdTe and $\mathrm{ZnS}$ nanocrystals as a modifier and stabilizer ${ }^{15,16}$. In the present study, the water-soluble glutathione modified CdSe quantum dots have been synthesized and the influence of synthesis condition on fluorescence intensity of quantum dots and their interaction with $\mathrm{Hg}^{2+}$ ions have been investigated.

\section{EXPERIMENTAL}

Selenium powder $(99.99 \%), \mathrm{Cd}(\mathrm{OAc})_{2} \cdot 2 \mathrm{H}_{2} \mathrm{O}(99.99 \%)$ and glutathione (98\%), were purchased from Aladdin Reagent Co. Ltd. $\mathrm{NaBH}_{4}(96 \%), \mathrm{NaOH}(85 \%)$ and $\mathrm{HgCl}_{2}(99.5 \%)$ were purchased from Sinopharm Chemical Reagent Co. Ltd. All reagents used were of analytical grade without further purification. The water used in the experiments was deionized to a resistively of $18.2 \mathrm{M} \Omega / \mathrm{cm}$.

Room temperature fluorescence (FL) spectra were recorded by a FL3-211-Pluminescence spectrometer (Jobin-Yvon, French). $\mathrm{X}$-ray diffraction analysis was performed using powder X-ray diffraction (Bruker D2, Germany).

Preparation of glutathione modified CdSe quantum dots were synthesized in an aqueous solution according to the literature procedure with some modification ${ }^{17}$. $0.1 \mathrm{mmol} \mathrm{Se}$ and 
$0.1 \mathrm{mmol} \mathrm{NaBH}_{4}$ were transferred into three-necked flask under $\mathrm{N}_{2}$-flow followed by the addition of $10 \mathrm{~mL}$ deionized water. The mixture was reacted under magnetic stirring in a water bath at $60^{\circ} \mathrm{C}$ for $1 \mathrm{~h}$ to form the colourless NaHSe solution. Then $0.3 \mathrm{mmol} \mathrm{Cd}(\mathrm{OAc})_{2} \cdot 2 \mathrm{H}_{2} \mathrm{O}$ was diluted to $100 \mathrm{~mL}$ in a three-necked flask in the presence of $0.9 \mathrm{mmol}$ glutathione as a stabilizing agent under $\mathrm{N}_{2}$-flow and the $\mathrm{pH}$ value was adjusted to 8 by dropwise addition of $1 \mathrm{M} \mathrm{NaOH}$ aqueous solution. The freshly prepared NaHSe solution was injected slowly into the $\mathrm{Cd}$ precursor solution under vigorous stirring. The molar ratio of $\mathrm{NaBH}_{4}: \mathrm{Se}_{\mathrm{Cd}^{2+}}$ :glutathione was fixed at 1:1:3:9. The resulting mixture was refluxed at $90{ }^{\circ} \mathrm{C}$ for $1 \mathrm{~h}$ under $\mathrm{N}_{2}$ atmosphere protection to promote the growth of quantum dots. Other $\mathrm{NaBH}_{4}: \mathrm{Se}_{\mathrm{Cd}^{2+}}$ :glutathione molar ratios $(2: 1: 3: 9,3: 1: 3: 9$, $4: 1: 3: 9,5: 1: 3: 9,6: 1: 3: 9$ and $3: 1: 3: 12,3: 1: 3: 15,3: 1: 3: 18)$ were investigated to optimize the reaction conditions.

The general procedure for $\mathrm{Hg}^{2+}$ detection was as follows: in a dry $10 \mathrm{~mL}$ volumetric flask, $0.5 \mathrm{~mL}$ PBS buffer solution was added. Then a series of $100 \mu \mathrm{L}$ different concentration $\mathrm{HgCl}_{2}$ standard solution was transferred into a $10 \mathrm{~mL}$ volumetric flask and finally diluted to $10 \mathrm{~mL}$ with water and mixed thoroughly. The relative fluorescence intensity was measured at $\lambda_{\mathrm{ex}}=430$ nm.

\section{RESULTS AND DISCUSSION}

In order to study the influence of $\mathrm{NaBH}_{4}$ concentration on the fluorescence intensity of glutathione modified CdSe quantum dots, the molar ratio of $\mathrm{Se}: \mathrm{Cd}^{2+}$ :glutathione keeps unchanged. Fig. 1 shows fluorescence spectra of synthesized $\mathrm{CdSe}$ quantum dots with the different molar ratio of $\mathrm{NaBH}_{4}: \mathrm{Se}$ : $\mathrm{Cd}^{2+}$ :glutathione. As the concentration of $\mathrm{NaBH}_{4}$ is increased, the fluorescence intensity is firstly enhanced and then weakened. For the CdSe quantum dots synthesized by high $\mathrm{NaBH}_{4}$ concentration, the low fluorescence intensity is due to the quenching effect of the fluorescence. Excessive $\mathrm{NaBH}_{4}$ can hydrolyze to form $\mathrm{NaBO}_{2}$, which hinders the combination of $\mathrm{Cd}^{2+}$ and NaHSe.

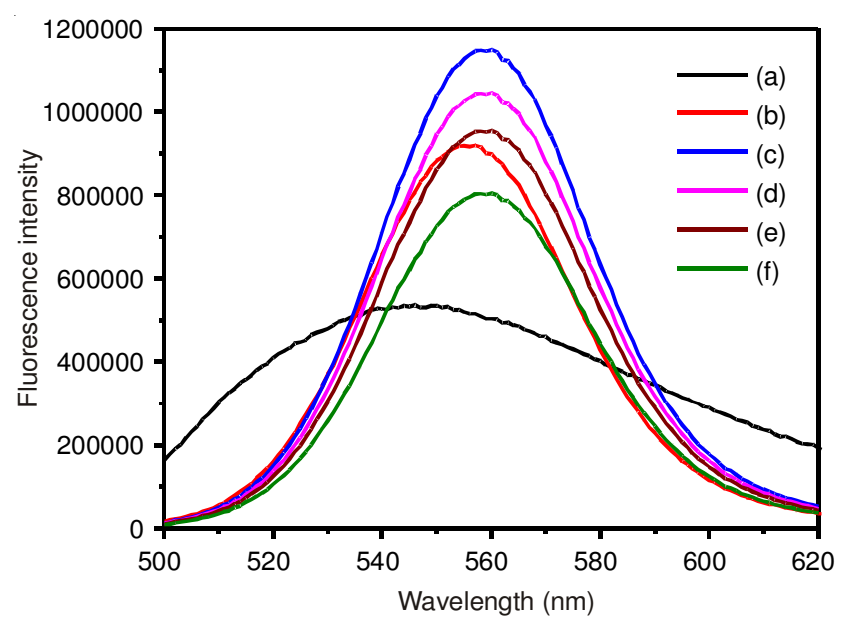

Fig. 1. Fluorescence spectra of synthesized CdSe quantum dots with the different molar ratio of $\mathrm{NaBH}_{4}: \mathrm{SeCd}^{2+}$ :GSH: (a) $1: 1: 3: 9$, (b) 2:1:3:9, (c) $3: 1: 3: 9$, (d) $4: 1: 3: 9$, (e) $5: 1: 3: 9$ and (f) $6: 1: 3: 9$

Glutathione has two - $\mathrm{COOH}$ group, which can provide further reactions and functional graft. So it is necessary to study the influence of glutathione concentration on the fluorescence intensity of glutathione modified CdSe quantum dots. Fig. 2 shows fluorescence spectra of synthesized CdSe quantum dots with the different molar ratio of $\mathrm{NaBH}_{4}: \mathrm{Se}$ : $\mathrm{Cd}^{2+}: \mathrm{GSH}$. As the concentration of glutathione is increased, the fluorescence is quenched.

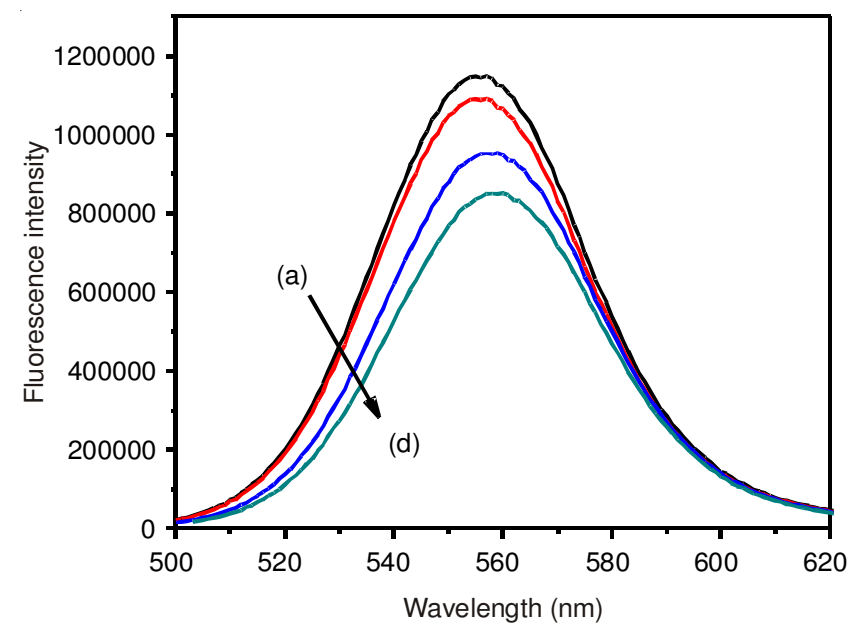

Fig. 2. Fluorescence spectra of synthesized CdSe quantum dots with the different molar ratio of $\mathrm{NaBH}_{4}: \mathrm{SeCd}^{2+}: \mathrm{GSH}$ : (a) $3: 1: 3: 9$, (b) $3: 1: 3: 12$, (c) $3: 1: 3: 15$ and (d) $3: 1: 3: 18$

Based on the above analysis, the optimum $\mathrm{NaBH}_{4}: \mathrm{Se}$ : $\mathrm{Cd}^{2+}$ :GSH molar ratio is obtained to be 3:1:3:9. The maximum $\lambda_{\text {em }}$ of glutathione modified CdSe quantum dots synthesized by the optimum process is $552 \mathrm{~nm}$. Fig. 3 gives XRD pattern of glutathione modified CdSe quantum dots synthesized by the optimum process. It is obvious that there is a single face centered cubic phase without impurity phase for glutathione modified CdSe quantum dots, according to JCPDS card No. 19-0191.

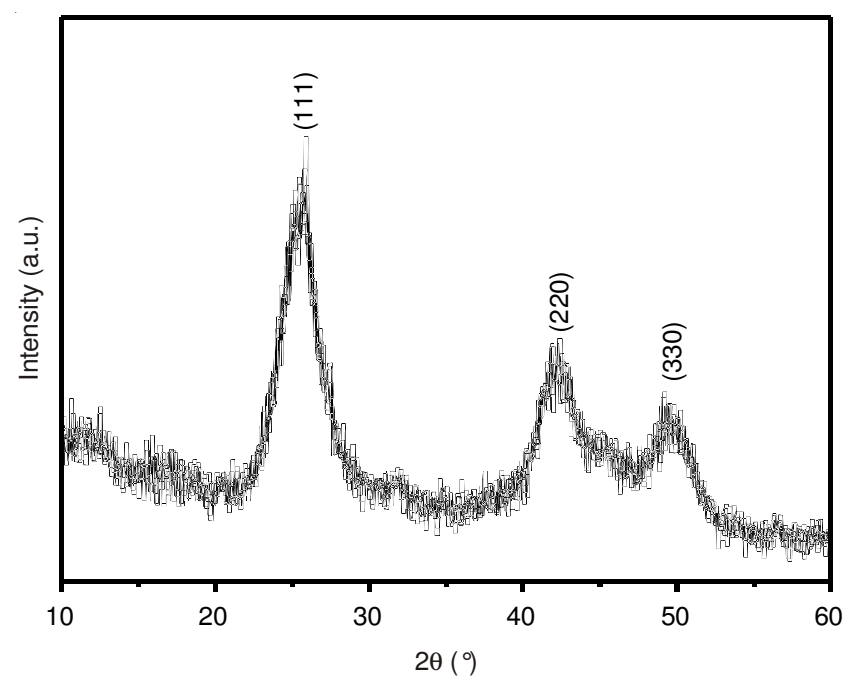

Fig. 3. XRD pattern of CdSe quantum dots synthesized by the optimum process

The glutathione modified CdSe quantum dots synthesized by the optimum process is used to detect $\mathrm{Hg}^{2+}$ ions. Fig. 4 shows fluorescence spectra of CdSe quantum dots in the presence of various concentration of $\mathrm{Hg}^{2+}$ ions in deionized 
water. As the concentration of $\mathrm{Hg}^{2+}$ ions is increased, the fluorescence intensity of glutathione modified CdSe quantum dots is significantly decreased. The low fluorescence intensity is due to the quenching effect of the fluorescence. The fluorescent properties of quantum dots are sensitive to their surface states. The fluorescence quenching phenomenon can be understood due to facilitating non-radiative $\mathrm{e}^{-} / \mathrm{h}^{+}$recombination annihilation on the surface of glutathione modified $\mathrm{CdSe}$ quantum dots resulting from an effective electron transfer process between the surface functional groups and $\mathrm{Hg}^{2+}$ ions base on the strong affinity with the functionalized CdSe quantum dots ${ }^{18}$. A linear relationship between $\Delta \mathrm{F} / \mathrm{F}_{0}\left(\mathrm{~F}\right.$ and $\mathrm{F}_{0}$ are the fluorescence intensities of glutathione modified CdSe quantum dots at given $\mathrm{Hg}^{2+}$ ions concentration and $\mathrm{Hg}^{2+}$-free solution, respectively and then $\Delta \mathrm{F}=\mathrm{F}_{0}-\mathrm{F}$ ) and the concentration of $\mathrm{Hg}^{2+}$ ions in the range from 0.3 to $15 \mu \mathrm{g} / \mathrm{L}$ (shown in the inset of Fig. 4) is found, which can be defined approximately by the relation $\Delta \mathrm{F} / \mathrm{F}_{0}=0.04513 \mathrm{C}+0.1682$.

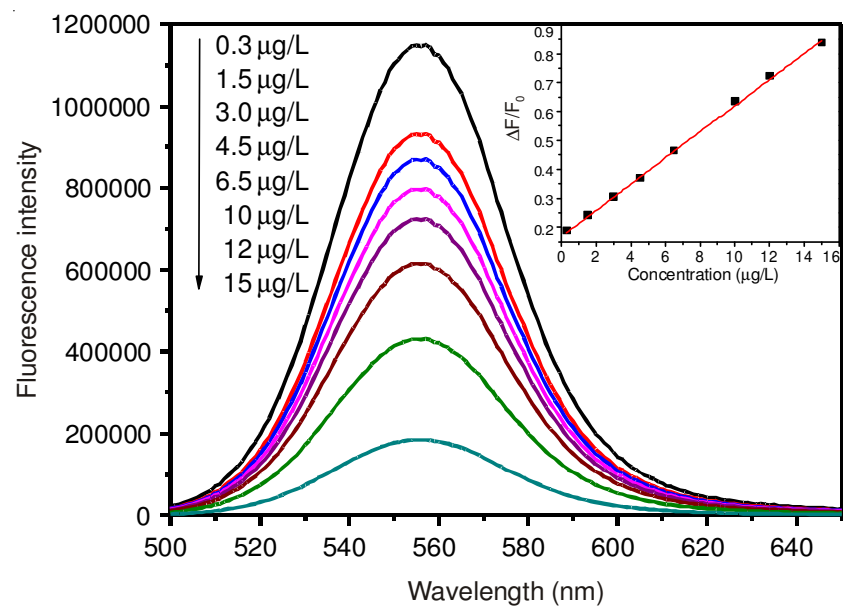

Fig. 4. Fluorescence spectra of CdSe quantum dots in the presence of various concentration of $\mathrm{Hg}^{2+}$ ions in deionized water. Inset show relationship between $\Delta \mathrm{F} / \mathrm{F}_{0}$ and the concentration of $\mathrm{Hg}^{2+}$ ions in deionized water.

\section{Conclusion}

A simple and environmentally benign process has been developed to synthesize water-soluble glutathione modified
CdSe quantum dots. As the concentration of $\mathrm{NaBH}_{4}$ is increased, the fluorescence is firstly enhanced and then quenched. On the other hand, the fluorescence is quenched with increasing the concentration of glutathione. Finally, the optimum $\mathrm{NaBH}_{4}: \mathrm{Se} \mathrm{Cd}^{2+}$ :GSH molar ratio is obtained to be 3:1:3:9. The fluorescence quenching occurred when $\mathrm{Hg}^{2+}$ ions interact with glutathione modified CdSe quantum dots. $\mathrm{Hg}^{2+}$ ions can be determined in the concentration range of 0.3-15 $\mu \mathrm{g} / \mathrm{L}$.

\section{ACKNOWLEDGEMENTS}

This research was supported by Zhejiang Provincial Science Foundation (No. Y6110475) and the Undergraduate Innovative Project of Zhejiang Province (No. 2012R409010).

\section{REFERENCES}

1. M. Kampa and E. Castanas, Environ. Pollut., 151, 362 (2008).

2. Y. Zhang and S.B. Adeloju, Talanta, 74, 951 (2008).

3. P. Cava-Montesinos, E. Ródenas-Torralba, Á. Morales-Rubio, M. Luisa Cervera and M. de la Guardia, Anal. Chim. Acta, 506, 145 (2004).

4. D.E. Nixon, M.F. Burritt and T.P. Moyer, Spectrochim. Acta B, 54, 1141 (1999).

5. Y. Han, Y. Li, W. Si, D. Wei, Z. Yao, X. Zheng, B. Du and Q. Wei, Spectrochim. Acta A, 79, 1546 (2011).

6. Y. Bonfil, M. Brand and E. Kirowa-Eisner, Anal. Chim. Acta, 424, 65 (2000).

7. H.A. Mckenzie and L.E. Smythe, Elsevier, New York (1998).

8. M.J. Bruchez Jr., M. Moronne, P. Gin, S. Weiss and A.P. Alivisatos, Science, 281, 2013 (1998).

9. H. Kuang, Y. Zhao, W. Ma, L.G. Xu, L.B. Wang and C.L. Xu, TrAC Trends Anal. Chem., 30, 1620 (2011).

10. B. Chen, Y. Yu, Z.T. Zhou and P. Zhong, Chem. Lett., 33, 1608 (2004).

11. A.M. Smith and S. Nie, Nat. Biotechnol., 27, 732 (2009).

12. J. Zhang, Y.J. Wan, Y.Y. Li, Q.F. Zhang, S.Q. Xu, H.J. Zhu and B.H. Shu, Environ. Pollut., 159, 1348 (2011).

13. Y. Chen, Z. Chen, Y. He, H. Lin, P. Sheng, C. Liu, S. Luo and Q. Cai, Nanotechnology, 21, 125502 (2010).

14. H.L. Tao, X.F. Liao, M.Z. Xu, S.H. Li, F.X. Zhong and Z.S. Yi, J. Lumin., 146, 376 (2014).

15. H.F. Qian, C.Q. Dong, J.F. Weng and J.C. Ren, Small, 2, 747 (2006).

16. Z.Q. Liu, P.F. Yin, H.P. Gong, P. Li, X. Wang and Y. He, J. Lumin., 132, 2484 (2012).

17. K. Zhang, J.K. Guo, J.J. Nie, B.Y. Du and D.J. Xu, Sens. Actuators B, 190, 279 (2014).

18. A.V. Isarov and J. Chrysochoos, Langmuir, 13, 3142 (1997). 